\title{
As três durações de Fernand Braudel no Ensino de História: proposta de atividade
}

\author{
The three durations of Fernand Braudel \\ in History teaching: a proposal of activity
}

Ricardo Marques de Mello*

\section{RESUMO}

$\mathrm{O}$ artigo apresenta o desenvolvimento de uma atividade com alunos da Graduação em História, Professores de História da rede básica de ensino e mestrandos em História acerca da presença múltipla das durações (curta, média e longa) no nosso dia a dia. Como base teórica, usei as ideias de Fernand Braudel (2007); como recurso metodológico, percorremos um trajeto predefinido dentro da cidade de Campo Mourão (PR), a fim de observar como o tempo se manifesta na cidade das mais diferentes formas. Entre os resultados mais evidentes, boa parte dos educandos conseguiu apurar sua percepção sobre como o tempo se expressa em objetos, valores e estabelecimentos, tanto com exemplos usados por eles, quanto mediante discussões que desnaturaram determinadas construções físicas, ideias e relações sociais. Palavras-chave: durações; Fernand Braudel; atividade extraclasse; ensino de História.

\section{Abstract}

This article presents the development of an activity with undergraduate students in History, History Teachers and Master's students in history focusing the multiple presence of durations (short, medium and long) in our daily life. As a theoretical basis, I used the Fernand Braudel's ideas (2007); as a methodological resource, we walk through the city of Campo Mourão (PR), in order to observe how time manifests itself in the most different forms. With this activity, I perceived that students improved their perception about how time is expressed in objects, values and establishments, both with examples used by them, and through discussions that denature certain physical constructions, ideas and social relations.

Keywords: durations; Fernand Braudel; extra class activity; History teaching.

\footnotetext{
* Doutor em História pela Universidade de Brasília (UnB). Professor na Universidade Estadual do Paraná (Unespar). Campo Mourão, PR, Brasil. ricardo.rmm@gmail.com
} 
Neste artigo apresento uma experiência didática cujo objetivo foi suscitar nos educandos a percepção de que valores, práticas e/ou objetos com os quais estamos envolvidos cotidianamente resultam de processos de longa, média e curta duração, baseando-me nas categorias formuladas por Fernand Braudel (2007). Ao mesmo tempo que exponho o desenvolvimento da atividade, descrevo suas etapas, já indicando de que maneira cada leitor(a)/professor(a) poderá realizá-la considerando suas próprias circunstâncias profissionais. $\mathrm{Na}$ primeira parte destaco a importância do tempo para o historiador e apresento um breve contexto intelectual sobre a publicação do artigo "História e Ciências Sociais: a longa duração", em que Braudel discorreu especificamente acerca das três durações. Em seguida, demonstro as estratégias que usei para explicar os conceitos de curta, média e longa duração e qual foi o comando para a realização da atividade extraclasse. Na sequência descrevo qual o trajeto percorrido fora de sala de aula, ilustro com fotos de alguns prédios que ganharam destaque na observação dos educandos e comento algumas de suas reflexões no debate realizado já de volta à sala de aula. Como arremate, menciono as impressões que tive após praticar essa atividade com alunos da Graduação em História, Professores de História da rede básica de ensino e mestrandos em história. ${ }^{1}$ Embora eu tenha executado a atividade no município de Campo Mourão (PR), considero não haver empecilho algum para que ela possa ser desenvolvida em outras cidades e regiões.

\section{PreÂMbulo}

A história enquanto ramo do conhecimento humano está imersa em muitas polêmicas. Não sabemos com precisão e sem hesitar, por exemplo, se ela é ciência ou arte, se é uma articulação entre ambas ou nenhuma das duas. Quase como um desdobramento desse embate, também temos dificuldade em caracterizar como explicamos o que se passou, o peso da narrativa no produto final de uma pesquisa ou em que medida os próprios historiadores interferem no processo de (re)construção do passado. Somam-se a isso questões relacionadas ao âmbito social. Por exemplo: de que maneira a organização sociopolítica contemporânea influi na historiografia, ou até que ponto as apropriações pelos mais diferentes grupos são pertinentes, desejados e/ou necessários? Já há algum tempo os 
teóricos das mais diferentes áreas analisam e propõem alternativas para essas questões, ainda que não se tenha dado a última palavra a nenhuma delas.

Todas essas interrogações, porém, são posteriores àquela que é a primeira e talvez a mais relevante: qual o objeto da historiografia? Seriam as questões políticas as mais importantes do passado? As sociais? As culturais? As econômicas? As administrativas? As grandes ideias? Um historiador que não se ocupa com nenhuma dessas dimensões da realidade pretérita produz, então, um trabalho menor? Eis a primeira grande dificuldade em delimitar o objeto historiográfico: os historiadores não têm um setor ou área específicos a serem investigados. A resposta imediata para a questão, ainda no século XIX, foi associar a história ao passado. O campo de trabalho dos historiadores, portanto, seria tudo o que se passou (Dosse; Delacroix; Garcia, 2012).

Muitos autores reagiram a essa assertiva. Marc Bloch (2001, p.52-55), por exemplo, refutou veementemente qualquer redução da história ao passado. Em resposta, defendeu a ideia de que a história é a ciência dos homens no tempo. Aparentemente simples, a frase de Bloch tem, ao menos, três pressupostos relevantes para o nosso assunto. O primeiro deles refere-se ao uso da palavra ciência. Diferentemente de outras formas de pensamento histórico, ou seja, saberes que se ocupam com a relação entre passado, presente e, por vezes, futuro, como a religião cristã e as memórias locais, a história, que também se dedica a essa relação, é uma ciência, o que, indubitavelmente, a promove a um patamar superior. A segunda diz respeito à dissociação entre história e passado para, no seu lugar, inserir a questão do tempo. Assim, o objeto principal da história deixa de ser o passado por si mesmo e passa a ser as suas relações com o presente. E, por fim, Bloch ressaltou o foco da história: o homem (entenda-se o ser humano). Uma história das invenções, das culturas agrícolas ou do clima, só faz sentido se estiver relacionada às mudanças e permanências na vida dos indivíduos, das sociedades. Hoje, a assertiva de Bloch é quase um lugar-comum.

Embora haja uma espécie de concordância subtendida e majoritária de que o tempo é o objeto primeiro dos historiadores, as tentativas de defini-lo mostraram-se insuficientes, quando não constrangedoramente ingênuas. Essa é uma dificuldade secular. Paul Ricoeur, por exemplo, lembrou-nos do embaraço de santo Agostinho frente ao tema: "Que é, pois, o tempo? Se ninguém me perguntar, eu sei; se o quiser explicar a quem me fizer a pergunta, já não 
sei" (Agostinho apud Ricoeur, 2010, p.17). Mais fácil que explicar o tempo é dizer que a história é uma disciplina (ou ciência) que se ocupa com ele.

Se pensar, compreender, descrever e explicar o que o tempo é nos trabalhos historiográficos, mesmo que usemos termos abstratos e raciocínios complexos, é uma tarefa árdua, mais difícil ainda é realizar essa atividade no ensino básico de história. É bem verdade que os livros didáticos, por exemplo, têm se empenhado sobremaneira para ir além de uma reflexão linear e contínua do tempo. Também é verdade que professores, de modo geral, se esforçam para adaptar os conteúdos programáticos às circunstâncias nas quais os alunos estão inseridos, destacando os elementos do passado que permanecem atuantes, o que é específico do nosso momento, e como somos seres históricos.

No entanto, precisamos avançar mais, termos mais opções e oportunidades, já que consumar a relação entre os conteúdos escolares e o tempo não é algo natural ou automático. Essa é uma ação que requer consciência, criatividade, dedicação e, em alguns casos, experiência profissional. Além disso, está sujeita a frustrações e insucessos: a sala de aula não é um ambiente previsível. E, por fim, o mundo contemporâneo tem recursos tecnológicos, dinâmica e, cada vez mais, características comunicativas que transformam o ensino de história em desafio constante. Não é fácil.

Para ampliar o nosso repertório de possibilidades de pensar de que modo o objeto privilegiado do historiador, o tempo, se manifesta na história, muitos autores trazem contribuições específicas, como Mircea Eliade (2001), Jörn Rüsen (2001; 2011; 2012), Norbert Elias (1998), Reinhart Koselleck (2006; 2013; 2014), Paul Ricoeur (2007; 2010), François Hartog (2015) etc., e tantos outros que, refletindo sobre teoria, filosofia da história e história da historiografia, acabam, invariavelmente, se ocupando com a questão do tempo no ofício dos historiadores. A bem da verdade, qualquer pesquisa ou obra historiográfica pode (ou deveria?) desencadear questões relacionadas ao tempo.

Um dos mais relevantes historiadores do século XX que inovou na discussão sobre o tempo é Fernand Braudel. Em um de seus textos mais conhecidos, "Histoire et Sciences sociales: La longue durée" (História e Ciências Sociais: a longa duração), publicado em 1958 na revista Annales. Économies, Sociétés, Civilisations ${ }^{2}$ o principal expoente da denominada segunda geração da École des Annales respondeu a uma das figuras mais proeminentes de sua 
época: Claude Lévi-Strauss, especificamente ao seu texto Anthropologie structurale (Antropologia estrutural), publicado no mesmo ano.

Lévi-Strauss sugeriu que a história não era uma ciência. Entre outros motivos, porque os historiadores dedicavam seus esforços aos fatos transitórios, efêmeros, momentâneos, o que seria insuficiente para identificar as estruturas e elementos constantes que regem as relações sociais. Em contraposição, a antropologia estrutural, cujo foco estava voltado à detecção das características perenes, constantes, independentes de tempo, circunstâncias e espaço, seria uma ciência no sentido estrito do termo e, portanto, estaria em uma escala acima da história na hierarquia das ciências sociais (Reis, 2008). Embora o debate tivesse um novo campo semântico e especificidades da França de meados do século XX, ele ressignificava uma antiga contraposição sublinhada por Aristóteles entre poesia e história e, de alguma maneira, era uma versão francesa do debate que ocorria em ambiente anglo-saxão sobre ciência, protociência e pseudociência, intensificado com a publicação do artigo The Function of general laws in History (A função de leis gerais em História), de Carl Hempel, em 1942 (Hempel, 2004).

A resposta de Braudel a Lévi-Strauss foi, em certo sentido, contemporizadora. Por um lado, ressaltou a relevância em investigar as estruturas para se compreender o passado e o presente humanos, e, por outro, enfatizou a necessidade de relacionar as estruturas aos acontecimentos para um esclarecimento mútuo: "nada é mais importante, a nosso ver, no centro da realidade social, do que essa oposição viva, íntima, repetida indefinidamente entre o instante e o tempo lento a escoar-se" (Braudel, 2007, p.43). Além de uma elegante resposta a Lévi-Strauss, Braudel reforçou a necessidade de se pensar uma aproximação contemporânea entre a história e as ciências vizinhas mediante a categoria do tempo longo, da longa duração, recusando modelos simplistas de análise e ressaltando a necessidade de uma compreensão simultânea das durações.

\section{A EXPLICAÇÃo DAS TRÊS DURAÇÕES DE BRAUdEL}

Para realizar essa atividade didática é importante conhecer bem em que circunstâncias "História e Ciências Sociais: a longa duração", de Braudel, foi publicado, porque aumenta nosso grau de consciência acerca da finalidade do artigo, seus detalhes e contexto. Embora seja uma etapa obrigatória para quem 
vai conduzir a atividade, é apenas uma parte do processo, que precisa ser aprofundado com um entendimento do que significa curta, média e longa duração.

A curta duração refere-se ao "tempo breve, ao indivíduo, ao evento" (Braudel, 2007, p.44). Quando publicou seu texto, Braudel associou-a à historiografia tradicional, nomeadamente à histoire événementielle dos historiadores metódicos, como Ch. Langlois, Ch. Seignobos, G. Monod e E. Lavisse, cuja narrativa factual baseava-se em documentos escritos e voltava-se, sobretudo, aos eventos políticos, destacando as ações de indivíduos notáveis que alteraram o curso da história. A curta duração, portanto, estava ocupada com os acontecimentos que marcaram cronologicamente o percurso de uma sociedade. É o tempo do cronista, do jornalista (Braudel, 2007, p.45). Em termos numéricos, ela pode se manifestar entre um dia e/ou alguns poucos anos. Eventos como Revolução Francesa (1789), a Independência das Treze Colônias Americanas (1776), a Revolução Russa (1917) ou a Proclamação da República no Brasil (1889) são exemplos de curta duração.

A média duração diz respeito a uma conjuntura, expressa em uma ou algumas décadas. "A nova história econômica e social põe no primeiro plano de sua pesquisa a oscilação cíclica e assenta sobre sua duração: prendeu-se à miragem, também à realidade das subidas e descidas cíclicas dos preços" (Braudel, 2007, p.44). Historiograficamente, Braudel situou os trabalhos focados na média duração como contrapontos do seu próprio tempo à história factual, de curta ou curtíssima duração:

Ontem, um dia, um ano podiam parecer boas medidas para um historiador político. O tempo era uma soma de dias. Mas uma curva dos preços, uma progressão demográfica, o movimento dos salários, as variações da taxa de juro, o estudo (mais imaginado do que realizado) da produção, uma análise precisa da circulação reclamam medidas muito mais amplas. (Braudel, 2007, p.47)

Já a história na longa duração só é compreensível quando visualizada em séculos, pois é estrutural: "para nós, historiadores, uma estrutura é sem dúvida, articulação, arquitetura, porém mais ainda, uma realidade que o tempo utiliza mal e veicula mui longamente. Certas estruturas ... tornam-se elementos estáveis de uma infinidade de gerações" (Braudel, 2007, p.49). Nela, a velocidade das mudanças é quase imperceptível para o indivíduo comum e, simultaneamente, indispensável para o tipo de historiografia que Braudel sugere: “é em 
relação a essas extensões de história lenta que a totalidade da história pode se repensar, como a partir de uma infraestrutura. Todas as faixas, todos os milhares de faixas, todos os milhares de estouros do tempo da história se compreendem a partir dessa profundidade, dessa semi-imobilidade; tudo gravita em torno dela" (Braudel, 2007, p.53).

Com o reconhecimento da curta, média e longa duração e, sobretudo, da atuação delas simultaneamente na história, Braudel não apenas reposicionou a ciência histórica no debate ante as demais ciências sociais, como também atribuiu novas perspectivas à relação entre passado, presente e futuro. Houve, assim, um novo entendimento de tempo (o objeto primeiro do historiador) e das múltiplas durações coexistentes. Compreender um fenômeno histórico passaria, então, pela análise da relação entre o evento, a conjuntura e a estrutura que subjaz a ambas.

Como atividade didática, além da conceituação proposta pelo próprio Braudel, é preciso realizar um profundo esforço para didatizar as expressões curta, média e longa duração sem tornar a explicação simplista e redutora. Para nossa sorte, as possibilidades de metáforas ilustrativas que cada um pode criar/ usar são numerosas e passíveis de adaptação às circunstâncias locais.

Nas ocasiões em que realizei essa atividade, quase sempre iniciei a explicação com a metáfora do rio: desenho no quadro uma imagem que representa um corte transversal em um suposto rio, muito profundo (pode-se substituir o rio pelo mar sem prejuízo). Nessa imagem devem ficar em destaque a superfície, a sua dimensão intermediária e o fundo do rio. Em cada uma dessas "alturas" a água do rio se movimenta com uma velocidade: na superfície ela é alta, no meio é fraca e no fundo é quase imóvel. Assim como o rio, as mudanças na história das sociedades apresentam três níveis de velocidade: rápida, intermediária e demorada. A primeira diz respeito aos fatos, como as revoluções, tomadas de poder que, em curto período (menos de uma década), alteram determinada configuração social, política, econômica, cultural; a esse grau de velocidade denominamos curta duração. A segunda refere-se às mudanças conjunturais, ou seja, àquelas alterações na organização social que ocorrem em algumas décadas; a esse grau de velocidade denominamos média duração. Por fim, a última está relacionada às estruturas que organizam e regulam a sociedade como um todo; as mudanças nesse nível são tão lentas que em uma geração não é possível percebê-las, apenas em uma retrospectiva de séculos é-nos 
permitido detectar mudanças nas estruturas; a esse grau de velocidade denominamos longa duração. Com essa primeira imagem, ressalto o fato de que o rio, assim como as mudanças na história, tem, em si, as três velocidades ocorrendo ao mesmo tempo. Essa observação é absolutamente relevante, pois cumpre a função de exemplificar a simultaneidade das durações e a interpenetração entre elas, o que, da minha perspectiva, é uma das principais funções da atividade.

Após ilustrar com a imagem do rio, interagir com os educandos, ilustrar com exemplos históricos e certificar-me de que não restam dúvidas acerca da metáfora, afirmo que cada um de nós carrega as três durações. No que se refere à longa duração, temos, por exemplo, valores milenares, como aqueles característicos do cristianismo - cito alguns e atento ao máximo para não incorrer drasticamente no anacronismo. No que diz respeito à média duração, exemplifico com a fundação da cidade em que atuo, na qual os educandos residem, e a respectiva identidade que nos forma, bem como assinalo os valores e práticas familiares, das duas gerações precedentes, que ainda lhes são caras. E em relação à curta duração, os casos são abundantes, como gostos musicais, valores da geração deles, gírias, moda, comportamentos etc. Assim como fiz com a metáfora do rio, finalizo essa estratégia didática destacando que as três durações estão presentes ao mesmo tempo e se imiscuem.

Com essas explicações iniciais os educandos começam a se familiarizar com o tema e sua abordagem. E é exatamente nesse momento que inicio uma explicação um pouco mais abstrata de como surgiu a ideia de Braudel, qual era o seu contexto, por que é importante para um historiador compreender a simultaneidade e indissociabilidade das durações e, sobretudo, como a história não é apenas uma disciplina escolar: somos históricos, fazemos, levamos a história e dela somos produtos. E mais do que isso: ainda que não percebamos, em tudo há história: na nossa casa, no bar, na rua, na organização da cidade, nas formas de tratamento... em qualquer situação é possível perceber a presença das três durações. Feito isso, iniciamos uma conversa em que os educandos podem apresentar exemplos, refletir, questionar, duvidar, enfim, se integrar definitivamente à discussão proposta.

Esse é o ponto de partida para a última etapa antes de sairmos de sala de aula: a explicação do comando. Nesse momento, informo-os que percorreremos determinado trajeto e peço que analisem de que maneira a curta, a média 
e a longa duração se expressam em objetos, prédios, pessoas etc. desse caminho. Tão importante quanto criar condições para que os alunos compreendam em que sentido o termo "duração" deve ser concebido e a importância do tempo em nossa vida abstratamente, é ressaltar e explicar que esses são conceitos materializados nos artefatos e ideias com os quais convivemos diariamente. Para finalizar o comando, dou a opção de levarem papel e lápis/caneta, fotografar ou simplesmente observar. ${ }^{3}$

\section{Trajeto EXTRACLASSE}

Já realizei essa atividade em 15 estados do Brasil, quando prestei consultoria pedagógica na área de História para uma editora privada. Neste artigo, porém, vou descrever especificamente como foram as experiências no município de Campo Mourão (PR), onde atuo como Professor Adjunto da Universidade Estadual do Paraná (Unespar). Nas quatro ocasiões em que tive oportunidade de conduzir esse trabalho, fizemos dois trajetos, um a pé, bem próximo à instituição, e outro com transporte da Universidade. Para facilitar o entendimento do que passarei a narrar, inseri as imagens que mais geraram reflexões e debates sobre as durações.

A Figura 1 mostra um bar que, no período noturno, recebe alguns alunos da Universidade e, por isso, se tornou ponto de encontro entre os estudantes, sobretudo nos finais de semestre, quando a estafa mental alcança seu pico de ação. Com base nesse bar, alguns educandos perceberam, de imediato, a relação entre a média e a curta duração: o prédio já abrigou bares antigos na cidade e tem algumas décadas de existência e de memórias (média duração). Além disso, até o ano passado, por exemplo, a fachada exprimia sua obsolescência frente aos seus concorrentes imediatos. Em 2016, contudo, houve uma reforma e a inclusão de imagens (algumas em estilo retrô) que associam o estabelecimento à famosa Route 66, com os ideais de juventude, liberdade e rebeldia que ela supostamente representa. Uma aluna complementou a descrição questionando se não poderíamos encontrar ali um elemento de longa duração, como a necessidade que vários agrupamentos humanos têm de se encontrar para celebrar ou lamentar a vida... Ela mesma citou exemplos históricos, o que ocasionou uma concordância generalizada de seus colegas. 


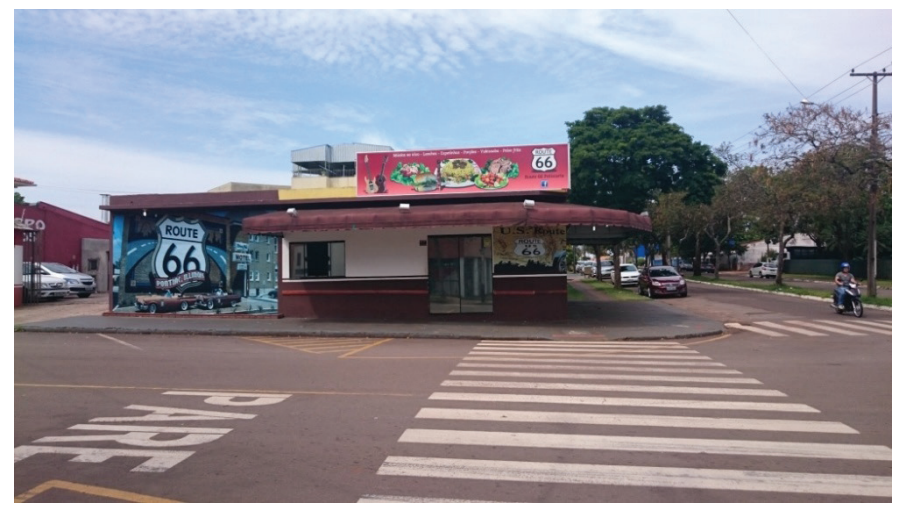

Figura 1 - Bar da esquina, 2016. Acervo pessoal.

A Figura 2 aparentemente retrata a sede de um partido político: o Partido do Movimento Democrático Brasileiro (PMDB). Esse prédio não apenas foi um dos mais comentados, como gerou reflexões muito interessantes. Entre elas, destaco a associação do PMDB à atuação dos indivíduos no espaço público desde a Grécia Antiga (longa duração), a configuração partidária brasileira pós-Estado Novo e a participação do MDB, origem do atual $\mathrm{PMDB}$, no período do regime militar (média duração) e, obviamente, os conchavos políticos nos quais o PMDB esteve envolvido nos últimos anos (curta duração). Uma das considerações meritórias sobre a imagem se deu quando um aluno cruzou as durações para pensá-las de forma concomitante, dizendo, por exemplo, que os discursos atuais ainda se valem da ideia de bem comum (muito remota) para supostamente angariar votos ou tomar medidas impopulares, sempre de acordo com as circunstâncias e necessidades de determinados grupos.

A Figura 3 é de um estabelecimento bem antigo na cidade: o Mercadão Municipal. Desde as primeiras décadas de existência do município, o Mercadão movimentou a cidade, com frutas, hortaliças, grãos e artesanato, entre outros artigos, majoritariamente de produtores locais. A crescente concorrência com os grandes supermercados fez a clientela se afastar e, consequentemente, os estabelecimentos que o compunham foram sendo gradativamente substituídos. Atualmente, o Mercadão abriga uma frutaria (em que boa parte da produção é oriunda de outros municípios e estados), algumas poucas lojas de artesanato (que resistem) e lojas variadas, principalmente com produtos 


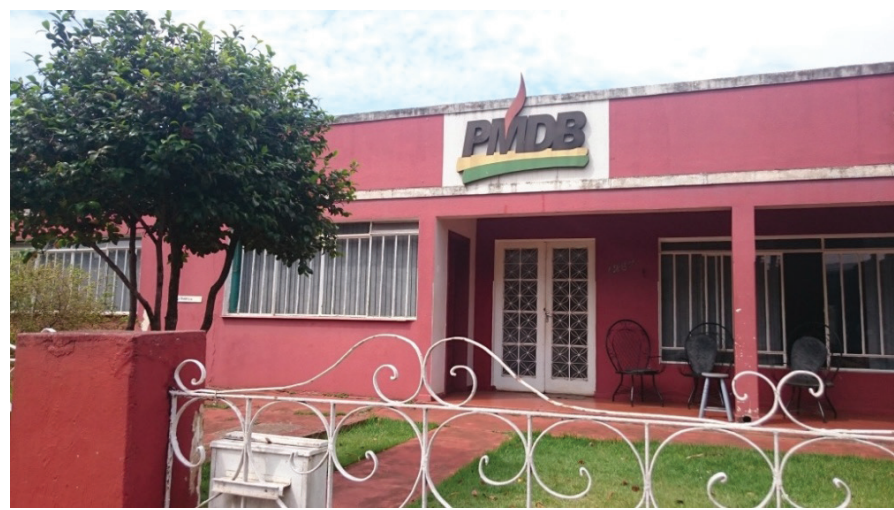

Figura 2 - Sede de partido político, 2016. Acervo pessoal.

importados da China. A longa, média e curta duração foram associadas respectivamente ao comércio na história da humanidade, às mudanças que o município atravessou nas últimas décadas e à atual configuração, com as lojas de eletrônicos.

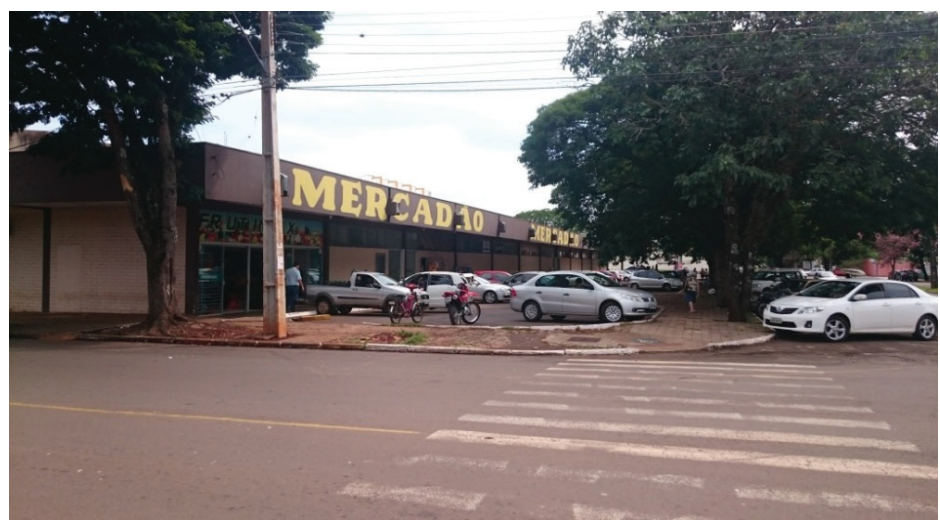

Figura 3 - Mercadão Municipal, 2016. Acervo pessoal.

A Figura 4 é do prédio do Serviço Nacional de Aprendizagem Comercial (Senac), um estabelecimento voltado a cursos e treinamentos para atender ao comércio. Assim como em outros casos, os educandos também fizeram várias digressões sobre as durações ali expressas. Mas, de modo geral, chamou-lhes a atenção a arquitetura do prédio, com suas colunas imponentes 
(remetendo-nos às colunas de obras arquitetônicas do mundo antigo) e os vidros espelhados (modernos).

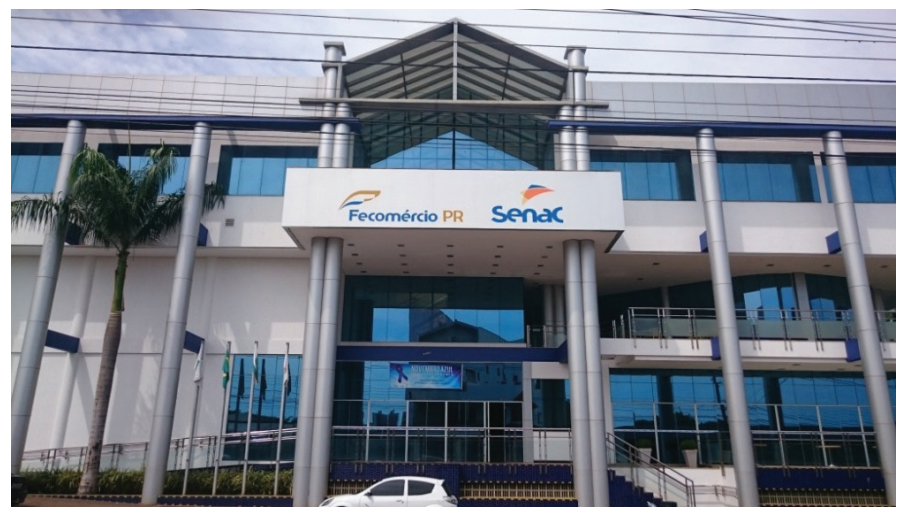

Figura 4 - Senac, 2016. Acervo pessoal.

Bons apontamentos dos educandos vieram da simples placa comercial retratada na Figura 5. Entre os principais, destaco a discussão, um tanto abstrata e atemporal, que nos remeteu ao período pré-histórico e à necessidade humana (cultural?) de registrar suas ações e o mundo que o cerca, bem como retransmiti-las às gerações vindouras. Supostamente, essa é uma necessidade que nos acompanha na longa duração. Em contraponto a essa primeira ponderação mais genérica, alguns alunos lembraram, quase simultaneamente, os copistas medievais e a invenção da imprensa no século XV. E, já na curta duração, foram recorrentes as menções às facilidades tecnológicas contemporâneas de reprodução gráfica, à conversão de livros em arquivos e até aos plágios, tão comuns quanto prejudiciais para o ensino e aprendizado atuais.

A Figura 6 retrata o Teatro Municipal. Novamente, houve associação quase imediata com o mundo grego antigo, o contexto político em que o prédio foi construído e o cenário conjuntural da cidade acerca das manifestações artísticas. A tônica aqui foi a relação entre arte e política, entre entretenimento e crítica, entre concessão e resistência ao longo do tempo.

Como não podia faltar, fomos ao núcleo da cidade: a praça da catedral (Figura 7), onde elementos de longa duração foram reconhecidos de pronto. Todavia, pouco tempo depois os próprios educandos começaram a questionar 


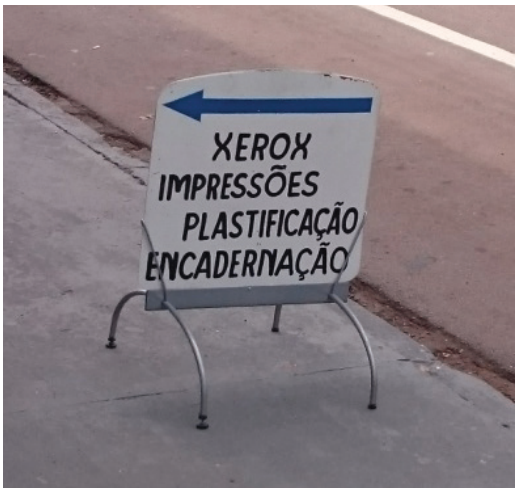

Figura 5 - Placa comercial, 2016. Acervo pessoal.

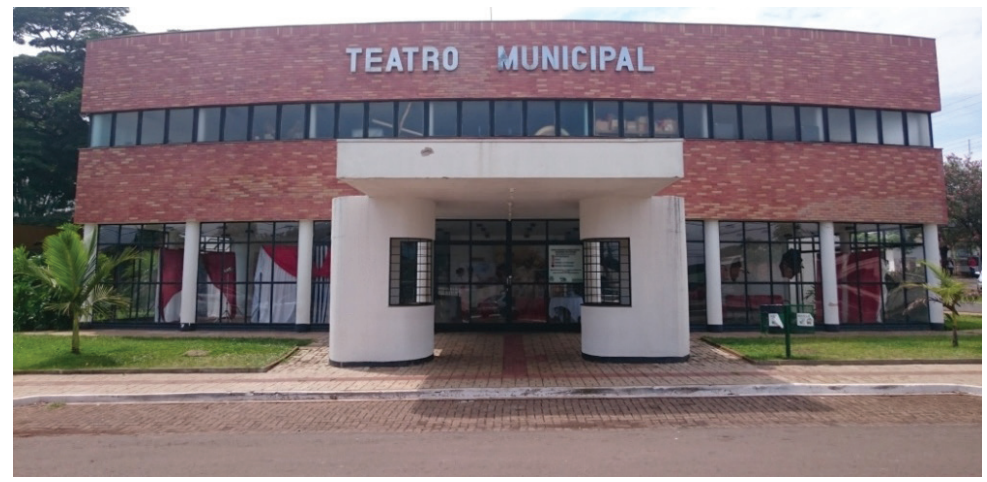

Figura 6 - Teatro Municipal, 2016. Acervo pessoal.

em que medida podemos pensar em permanências ou em ressignificações. Um dos professores da rede básica que participou da atividade e desenvolve pesquisa sobre história local fez breve exposição do papel da elite religiosa de Campo Mourão no período 1964-1985, ressaltando como grupos contrários ao regime foram sendo deslocados para outras regiões. Vários outros aspectos foram destacados, como as características arquitetônicas, as adaptações atualíssimas para evitar a evasão de fiéis e a participação de religiosos da igreja matriz na discussão municipal sobre questões de gênero, em que se fez a defesa 
de supostos valores milenares, ameaçados pelo que ficou conhecido como "ideologia de gênero".

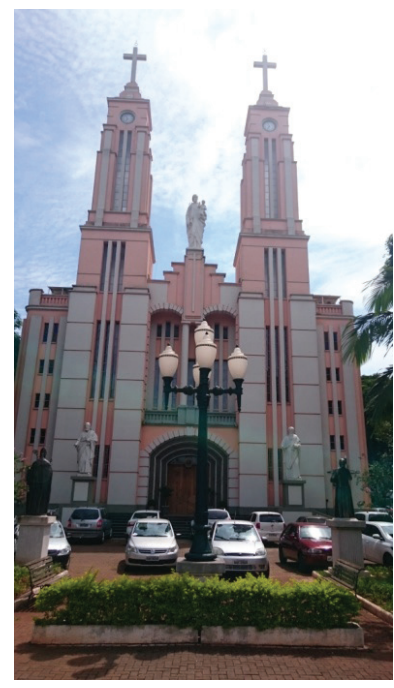

Figura 7 - Catedral Católica, 2016. Acervo pessoal.

Mas nas questões religiosas não ficamos apenas com a Igreja Católica Apostólica Romana. Passamos também em frente à Igreja Católica Ucraniana e à Luterana (Figura 8), quando emergiram considerações acerca da imigração, relação entre religião e cultura (identidade/alteridade) e marcas de distinção social. A principal dúvida levantada por um aluno sobre a Luterana foi: considerando as ideias de Max Weber em A ética protestante e o espírito do capitalismo (2013), a Reforma de Lutero foi um evento de curta duração que alterou elementos estruturais? Boas reflexões...

Mas nem só do externo nos nutrimos para (re)pensar o tempo. Chegou a hora de analisar a nossa própria instituição. A Figura 9 retrata a porta de entrada da Unespar, campus de Campo Mourão, com uma árvore, a araucária, símbolo do Paraná, bem à frente. Corretamente, nossa Universidade, enquanto instituição de ensino, foi associada a outras instituições de natureza semelhante, como as academias gregas, as universidades modernas e os colégios contemporâneos. Apesar das diferenças entre elas, há elementos perenes, que foram classificados como de longa duração. A existência da instituição e as mudanças pelas quais passou nos últimos 40 anos - de municipal a faculdade estadual e a 


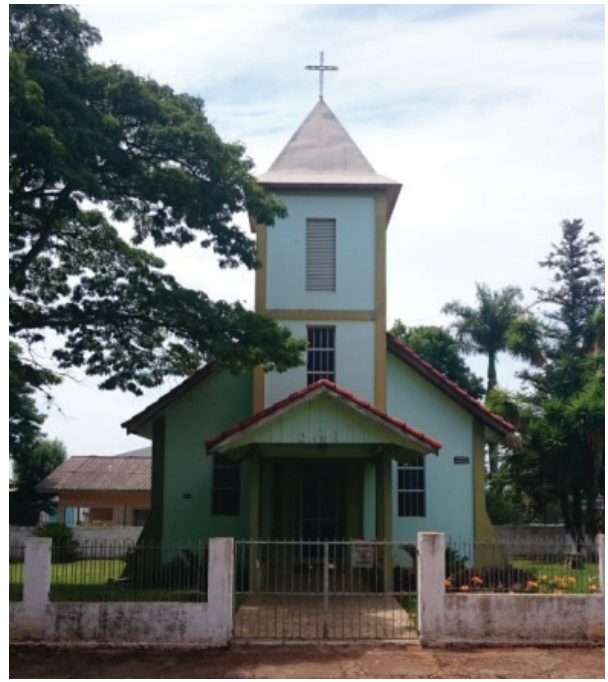

Figura 8 - Igreja Luterana, 2016. Acervo pessoal.

universidade -, bem como a necessidade de criar uma identidade cultural, com a araucária, para uma região (o estado do Paraná) que emergiu como uma colcha de retalhos ilustram mudanças e esforços de média duração.

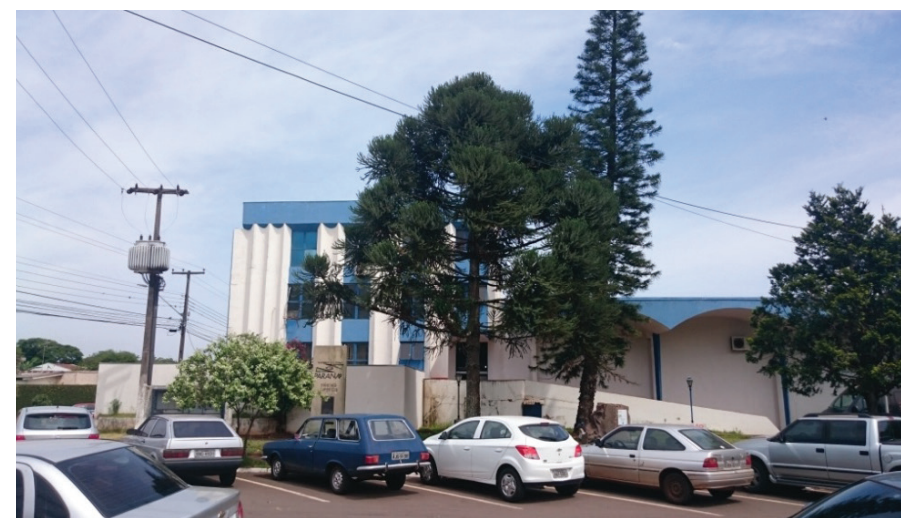

Figura 9 - Unespar, Campo Mourão, 2016. Acervo pessoal.

Obviamente, as imagens que expus aqui representam uma pequena parcela de tudo que foi explorado. Além disso, nossas reflexões com frequência 
ultrapassaram questões vinculadas a prédios e estabelecimentos. Talvez seja mesmo possível concluir que as principais discussões se deram no campo dos valores.

\section{CONSIDERAÇÕES FINAIS}

Após a condução várias vezes repetida dessa atividade, tenho algumas impressões bem pessoais que talvez possam ser úteis a quem está hesitante em colocá-la em prática. A primeira delas é que há certa vulgarização dos conceitos de Fernand Braudel. Não tem jeito: por mais que eu tenha trabalhado com o texto em si, a própria adaptação dos termos à realidade circundante acabou por reduzir um pouco a riqueza conceitual. A segunda impressão afirma que a anterior é irrelevante: não pretendi fazer dos educandos miniespecialistas em Braudel, mas instigá-los a pensar que o tempo, suas extensões e a maneira como elas se interpenetraram e se materializaram de maneiras aparentemente naturais estão presentes no nosso dia a dia. Com isso, foi possível demonstrar que em tudo há história e que essa disciplina está muito aquém e, simultaneamente, muito além dos bancos escolares.

Ademais, percebi que é muito difícil tratar a questão do tempo sem tocar em temas mais específicos. Por exemplo: quando iniciamos a reflexão sobre a sede do PMDB, foi inevitável adentrarmos questões sobre a coisa pública, o papel do indivíduo na política e a participação popular. No que se refere ao Mercadão Municipal, houve intensas discussões sobre a relação entre mídia, capitalismo e política. No momento em que debatemos a nossa própria instituição de ensino, não foi diferente, assim como em todas as outras ocasiões: a questão do tempo e suas durações está acoplada a temas que, na verdade, são a expressão desse mesmo tempo. Isso me levou a outra impressão, que é também uma advertência a quem for conduzir esta atividade: o perigo do anacronismo, das generalizações e das fórmulas fáceis ronda as interpretações nos debates dos educandos. É necessário cuidado para não endossar avaliações aligeiradas ou, por outro lado, dar alguma questão por encerrada.

Uma última impressão: esta é uma atividade que tem mais benefícios que o contrário. Ela, de fato, desperta o interesse dos alunos, estimula o raciocínio e abre novas oportunidades de entendimento da realidade na qual estamos espontaneamente inseridos, mostrando que em tudo há história, ampliando a 
perspectiva que eles têm da nossa disciplina e propiciando um ensino significativo. Mais do que isso: ela contribui de forma leve à discussão sobre o objeto da história e sua materialidade, a simultaneidade de durações e a riqueza de possibilidades que temos ao pensar historicamente os fenômenos humanos. Se conceituar o tempo é uma tarefa árdua e propensa a aporias, como sugeriu a frase de santo Agostinho, criar condições para entendê-lo nas mais prosaicas situações pode ser uma alternativa interessante, eficaz e muito prazerosa.

\section{REFERÊNCIAS}

BLOCH, Marc. Apologia da história ou o ofício de historiador. Trad. André Telles. Rio de Janeiro: Jorge Zahar, 2001.

BRAUDEL, Fernand. História e Ciências Sociais: a longa duração. In: Escritos sobre a História. Trad. J. Guinburg e Tereza Cristina Silveira da Mota. São Paulo: Perspectiva, 2007. p.41-78.

DOSSE, François; DELACROIX, Christian; GARCIA, Patrick. As correntes histórias na França: séculos XIX e XX. Trad. Roberto Ferreira Leal. Rio de Janeiro: Ed. FGV, 2012.

ELIADE, Mircea. O sagrado e o profano. São Paulo: Martins Fontes, 2001.

ELIAS, Norbert. Sobre o tempo. Trad. Vera Ribeiro. Rio de Janeiro: Jorge Zahar, 1998.

HARTOG, F. Regimes de historicidade: presentismo e experiências do tempo. Trad. Andréa Souza de Menezes [et al.]. Belo Horizonte: Autêntica, 2015.

HEMPEL, Carl. A Função de Leis Gerais em História. In: GARDINER, Patrick. Teorias da História. 5.ed. Trad. Vítor Matos e Sá. Lisboa: Fundação Calouste Gulbenkian, 2004. p.421-435.

KOSELLECK, R. Estratos do tempo: estudos sobre História. Trad. Markus Hediger. Rio de Janeiro: Contraponto; Ed. PUC-Rio, 2014.

. Futuro passado: contribuição à semântica dos tempos históricos. Trad. Wilma Patrícia Maas e Carlos Almeida Pereira. Rio de Janeiro: Contraponto; Ed. PUC-Rio, 2006.

et al. O conceito de História. Trad. René Gertz. Belo Horizonte: Autêntica, 2013.

LÉVI-STRAUSS, Claude. Anthropologie structurale. Paris: Plon, 1958.

REIS, José C. História da História (1950/1960). História e Estruturalismo: Braudel versus Lévi-Strauss. História da Historiografia, n.1, p.8-18, ago. 2008. 
RICOEUR, Paul. A memória, a história, o esquecimento. Trad. Alain François. Campinas: Ed. Unicamp, 2007.

Tempo e narrativa: a intriga e a narrativa histórica. Trad. Claudia Berliner. São Paulo: Martins Fontes, 2010. v.1.

RÜSEN, Jörn. Aprendizagem histórica: fundamentos e paradigmas. Curitiba: W.A. Editores, 2012.

. Razão Histórica. Teoria da História: os fundamentos da ciência histórica.

Trad. Estevão Martins. Brasília: Ed. UnB, 2001.

et al. Jörn Rüsen e o ensino de história. Trad. Marcos Roberto Kusnick [et al.]. Curitiba: Ed. UFPR, 2011.

WEBER, Max. A ética protestante e o espírito do capitalismo. Trad. José Marcos Mariani de Macedo. São Paulo: Companhia das Letras, 2004.

\section{NOTAS}

${ }^{1}$ Embora eu não tenha praticado essa atividade com educandos do Ensino Médio, considero plenamente possível desenvolvê-la nesse nível de ensino.

${ }^{2} \mathrm{O}$ texto original de Braudel está disponível na íntegra em http://www.persee.fr/issue/ ahess_0395-2649_1958_num_13_4; Acesso em: 25 nov. 2016.

${ }^{3}$ É possível realizar essa atividade sem sair da sala de aula: basta substituir a caminhada fora da sala por slides com imagens, de preferências instigantes.

Artigo recebido em 28 de novembro de 2016. Aprovado em 12 de janeiro de 2017. 